\title{
NA MORADA DO "INDIFERENTE" DESTINO (Análise do conto "A cartomante" de Machado de Assis)
}

Francine Fernandes Weiss

Mestranda em Teoria Literária

Universidade Estadual Paulista

\section{Resumo:}

"Na morada do "indiferente" Destino" aborda o conto "A cartomante" de Machado de Assis à luz das teorias da recepção. Através de um estudo do processo de composição do narrador no conto, analisa-se o projeto de leitor implícito ao texto machadiano. Discute-se, também, a especialidade da ironia utilizada na construção de ambas as figuras (narrador e leitor implícito): através da mobilidade na focalização o conto vai, sucessivamente, desautorizando a adesão emocional ao texto e solicitando do leitor uma postura crítica em relação à obra literária. A soma de tais processos confere a "A Cartomante" sua indiscutível modernidade.

\section{UMA QUESTÃO DE PONTO DE VISTA}

O conto "A cartomante" (MACHADO DE ASSIS, 7) se inicia com o narrador posicionado de modo superior em relação aos personagens e filtrando a visão que teremos dos mesmos. Já no primeiro parágrafo, uma fala da personagem Rita é tornada equivalente a outra do príncipe Hamlet, de Shakespeare. Tal equivalência - estabelecida pelo narrador e diretamente ligada aos acontecimentos que envolvem uma visita da personagem a uma cartomante - será absolutamente importante para uma posterior tentativa de leitura das lacunas deixadas pelo texto (ver ISER, 5) e, de saída, cava um abismo intelectual entre quem narra e sua personagem. Se o primeiro cita Shakespeare, a segunda nem ao menos sabia "que traduzia Hamlet em vulgar".

De qualquer forma, este narrador não toma parte direta na seqüência de eventos, cabendo-lhe apenas relatá-los. Ocupa, no entanto, uma posição de mediador. Está em um nível de conhecimento intermediário às posições do leitor e dos personagens. Como é onisciente, detém a totalidade do saber sobre o que se passou e fornece ao leitor as informações (não necessariamente neutras) acerca dos personagens e dos acontecimentos em que estes se envolveram (ver FRIEDMAN, 3).

Apesar disto, todo o texto se constrói como que por uma espécie de ordenação de uma grande variedade de pontos de vista sobre os eventos à medida em que eles vão ocorrendo. É como se o narrador fosse cedendo a focalização aos personagens e adotasse tal cessão como técnica narrativa (ver ISER, 4). Este processo, porém, não elimina, em nenhum momento a sua supervisão geral dos fatos. Mesmo quando cede a focalização a um personagem ou outro permitindo a representação literal de um seu diálogo ou pensamento, tal cessão vem sempre cercada da presença onisciente que tudo organiza e, ao ceder a palavra, o faz estrategicamente.

Trata-se de um claro jogo de perspectivas que são retomadas e que mudam quando opostas umas às outras. Do jogo destas perspectivas resulta uma visão que nada tem a ver com cada uma delas, mas revela uma nova visão, totalmente diferente das outras, organizada pela onisciência do narrador, ele mesmo uma visão. (ver ISER, 4)

Assim, o conto começa focalizando a figura de Rita primeiro através do narrador (que já a desmerece intelectualmente) e, a seguir, através de própria fala da personagem. Esposa de Vilela, grande amigo de Camilo, ela está tendo um caso amoroso com o segundo. Este caso é que lhe desperta a necessidade de recorrer a uma cartomante. Camilo, evitando despertar suspeitas no amigo, ultimamente escasseara suas visitas ao casal e Rita, insegura, duvidava da sinceridade de seu amor. 
A visita à cartomante é um importante recurso caracterizador da personagem. Rita fica convencida da verdade do que a adivinha "lê" nas cartas: Camilo continua a amá-la. Este, incrédulo e irônico, ouve, "por outras palavras" que há mais mistérios no céu e na terra do que supõe a nossa filosofia. E como ele ainda graceja, Rita arremata (em discurso indireto): "Se ele não acreditava, paciência; mas o certo é que a cartomante adivinhara tudo. Que mais? A prova é que ela agora estava tranquila e satisfeita."(p. 10)

Ora, tais fatos (e falas) dizem tanto da função que a cartomante parece desempenhar na vida da personagem que a procurou (restituir-lhe a tranquilidade e a satisfação) quanto da própria credulidade de Rita que se baseia em "evidências" emocionais. Uma vez que a fala da cartomante restituiu-lhe a paz desejada, isto passava a ser prova de que esta realmente adivinhara tudo.

Quando o narrador passa a revelar a posição de Camilo, tal certeza é questionada. Divergindo da opinião de Rita, ele é caracterizado como um cético. E é como cético que ouve o relato da amada:

\begin{abstract}
"Cuido que ele ia falar, mas reprimiu-se. Não queria arrancar-lhe as ilusões. Também ele, em criança, e ainda depois, foi supersticioso, teve um arsenal inteiro de crendices que a mãe lhe incutiu e que aos vinte anos desapareceram. No dia em que deixou cair toda essa vegetação parasita, e ficou só com o tronco da religião, ele, como tivesse recebido da mãe ambos os ensinos, envolveuos na mesma dúvida, e depois em uma só negação total. Camilo não acreditava em nada. Por quê? Não poderia dizêIo, não possuía um só argumento; limitava-se a negar tudo. $E$ digo mal, porque negar é ainda afirmar, e ele nào formulava a incredulidade; diante do mistério, contentou-se em levantar os ombros, e foi andando." (MACHADO DE ASSIS, 7, p. 10-1)
\end{abstract}

A atitude de Camilo é de distanciamento (ver BOOTH, 1). Mas, tal distanciamento se dá apenas quanto a suas convicções. Em termos afetivos, ele está intimamente ligado a Rita. Por outro lado, se a visão que Camilo tem diante da cartomante é diversa da de Rita, a diferença é apenas superficial. Da mesma forma que está evidenciada a fragilidade da convicção de Rita, o texto evidencia a fragilidade da falta de fé de Camilo. Tanto um quanto o outro tomam posições superficiais "diante do mistério". Rita adere acriticamente à satisfação emocional proporcionada pela fé. Camilo ri da atitude da amada e, também sem auto-crítica, adota uma quase incredulidade (já que, segundo o texto, ele sequer a formula). Sem "um único argumento", ele é muito parecido com Rita.

Iniciado o conto por esta cena inicial em que o casal conversa sobre a visita à cartomante, segue-se um flash-back em que se tem a "explicação das origens" da aventura em andamento. Então, a posição do narrador em relação a seus personagens começa a se explicitar melhor.

Camilo é caracterizado como um homem fraco. Não tomando decisões por si mesmo, vivera durante algum tempo na ociosidade, substituída depois por um emprego público, arranjado pela mãe. O narrador, nota-se, distancia-se moral e afetivamente de Camilo. Não atenua fraquezas do personagem, e a elas se refere com agudeza inquestionável:

"(...) Camilo era um ingênuo na vida moral e prática. FaltavaIhe tanto a ação do tempo, como os óculos de cristal, que a natureza põe no berço de alguns para adiantar os anos. Nem experiência, nem intuição." (MACHADO DE ASSIS, 7, p. 12)

O processo fica evidenciado na ironia utilizada quando da morte da mãe do personagem:

"Pouco depois morreu a mãe de Camilo, e nesse desastre, que $o$ foi, os dois mostraram-se grandes amigos dele. Vilela 
cuidou do enterro, dos sufrágios e do inventário; Rita tratou especialmente do coração, e ninguém o faria melhor." (MACHADO DE ASSIS, 7, p. 13)

Ora, a morte da mãe foi um desastre exatamente pela falta de autonomia do personagem. É o casal de amigos que vai tratar, inclusive de resolver os problemas práticos ligados à morte. Ou melhor, é Vilela quem o faz. Rita cuida do coração de Camilo e é precisamente nesta ocasião que a intimidade já existente entre eles lança raízes mais fundas e se transforma em algo mais. Sem a mãe, Camilo parece se tornar, agora, dependente de Rita. E a ironia do parágrafo citado volta-se também sobre ela: "ninguém o faria melhor".

O narrador evidenciará, também, seu distanciamento afetivo e moral com relação a Rita. Já se referira a ela como "dama formosa e tonta" e vem cercá-la de sugestões de limitação intelectual: as damas e o xadrez que ela jogava mal, as "palavras vulgares", ou "mal compostas" com que ela se expressava. Cercá-la também de sugestões de corrupção moral, de leviandade:

\begin{abstract}
"Camilo quis sinceramente fugir, mas já não pôde. Rita, como uma serpente, foi-se acercando dele, envolveu-o todo, fez-Ihe estalar os ossos num espasmo, e pingou-Ihe o veneno na boca. Ele ficou atordoado e subjugado. Vexame, sustos, remorsos, desejos, tudo sentiu de mistura; mas a batalha foi curta e a vitória delirante. Adeus, escrúpulos! Não tardou que o sapato se acomodasse ao pé, e aí foram ambos, estrada fora, braços dados, pisando folgadamente por cima de ervas a pedregulhos, sem padecer nada mais que algumas saudades, quando estavam ausentes um do outro. A confiança e a estima de Vilela continuavam a ser as mesmas." (MACHADO DE ASSIS, 7, p. 14)
\end{abstract}

A visão que o narrador fornece de Rita é absolutamente negativa. Ela é comparada à imagem de uma serpente: toda perfídia, toda veneno, envolvendo a fraqueza de Camilo. Este é tão covarde (vexame, sustos, remorso) quanto fraco (a batalha foi curta e vitória delirante). E, juntos, fazem o par perfeito: 0 sapato e o pé.

Um acomodado ao outro, todo drama moral fica esquecido. Nem a amizade, nem o amor de Vilela são lembrados e, durante algum tempo, o casal até convive normalmente com este. A censura do narrador vem no contraponto entre as atitudes: "A confiança e a estima de Vilela continuavam a ser as mesmas." Tal sentença dispensa, de sua parte, qualquer comentário. A atitude de Vilela, sempre fiel, acentua a indignidade do casal que era objeto de um afeto sincero.

Representados como seres de baixa consistência moral e mesmo intelectual, até o drama existencial dos dois (ou de Camilo, o único a apresentá-lo) é brevíssimo. "Adeus, escrúpulos!" é o comentário irônico do narrador que anuncia a consumação do adultério.

Começam, então, a ser enviadas cartas anônimas a Camilo, chamado, nelas, de "imoral e pérfido". Imoral por violar a convenção social da fidelidade no matrimônio, pérfido por desconsiderar a sinceridade do amigo. As cartas anônimas fornecem uma visão crítica do comportamento do casal: com esta nova visão, o idílio de esquecimento em que ambos se recolheram é perturbado. Na caracterização de Camilo, medo e covardia são reiterados. Na de Rita, leviandade e inconseqüência.

E, subitamente, Vilela altera seu comportamento: "começou a mostrar-se sombrio, falando pouco, como desconfiado." (p.16) É quando Camilo, já comunicado da alteração, recebe um bilhete:

"No dia seguinte, estando na repartição, recebeu Camilo este bilhete de Vilela: "Vem já, já, à nossa casa; preciso falar-te sem demora." Era mais de meio-dia. Camilo saiu logo; na rua, advertiu que teria sido mais natural chamá-lo ao 
escritório; porque em casa? Tudo indicava matéria especial, e a letra, fosse realidade ou ilusão, afigurou-se-Ihe trêmula. Ele combinou todas essas cousas com a notícia da véspera." (MACHADO DE ASSIS, 7, p. 16)

Segue-se, então, um processo cuidadoso de exploração psicológica do personagem. Misterioso, o bilhete poderia significar tudo: fosse ilusão ou realidade... O narrador, por sua vez, mantém o suspense. E o resultado é um momento de forte tensão em que a dúvida entre a novidade de uma descoberta e a normalidade da ocultação serão estudadas e avaliadas por Camilo. Haviam sido descobertos? E ele encontrava argumentos que tornavam tal fato provável. Ou seria um assunto de rotina que movia o amigo? Havia, também, como entender o bilhete assim.

O drama da dúvida, da incapacidade de assumir uma opinião e, sobretudo, de agir em função dela é tão intenso que leva Camilo quase à inação. A caminho da casa de Vilela, encontra um obstáculo e um apoio:

\begin{abstract}
"Quase no fim da rua da Guarda Velha, o tílburi teve de parar; a rua estava atravancada com uma carroça, que caíra. Camilo, em si mesmo, estimou o obstáculo, e esperou. No fim de cinco minutos, reparou que ao lado, à esquerda, ao pé do tílburi, ficava a casa da cartomante, a quem Rita consultara uma vez, e nunca ele desejou tanto crer na lição das cartas. Olhou, viu as janelas fechadas, quando todas as outras estavam abertas e pejadas de curiosos do incidente da rua. Dir-se-ia a morada do indiferente Destino." (MACHADO DE ASSIS, 7, p. 18)
\end{abstract}

Antes de mais nada, a própria maneira como o obstáculo se interpõe a Camilo e seu destino é bastante singular. Considerando-se o momento em que o personagem se encontrava, a circunstância de parar o tílburi justamente ao lado da casa da cartomante já é bastante impressionante. Além disto, a cartomante poderia vir a significar a solução para o impasse em que ele se encontrava: se advertido da verdade de suas suspeitas, ele talvez pudesse se proteger (ou fugir?).

A dúvida era em si mesma insuportável. Tão insuportável que o personagem "deseja" crer nas cartas. Desejar crer nas cartas é aceitar "qualquer" ajuda na hora extrema em que se encontra: qualquer uma, mesmo aquela de que se rira em outra ocasião. Ir à cartomante deve-se então, no caso de Camilo, à sua sensação de desespero no instante em que se dirige à casa de Vilela.

Agravante: tendo ele sido um cético, a visita à cartomante adquire um sentido que confere ainda maior desequilíbrio à situação e contribui ainda mais para que se forme uma visão negativa do personagem. Além de tudo, suas convicções revelam-se inconsistentes, adequando-se à necessidade do momento. Outra vez, ele é semelhante a Rita e as ações que iniciam e encerram o conto tornam-se, assim similares.

Similares, confirmam a função desempenhada pela cartomante na mente atormentada de um e outro personagem: representar "o indiferente Destino", e, através deste poder, restituir a paz. Como Rita, Camilo recorre ao universal cabedal de argumentos a favor do inexplicável:

"(...) Camilo fechava os olhos, pensava em outras cousas; mas a voz do marido sussurrava-lhe às orelhas as palavras da carta: "Vem já, já ..." E ele via as contorções do drama e tremia. A casa olhava para ele. As pernas queriam descer e entrar... Camilo achou-se diante de um longo véu opaco... pensou rapidamente no inexplicável de tantas cousas. A voz da mãe repetia-lhe uma porção da casos extradordinários, e a mesma frase do príncipe da Dinamarca reboava-Ihe dentro: "Há mais cousas no céu e na terra do que sonha a nossa filosofia..." Que perdia ele, se ...? 
Assim, a personagem da cartomante já se encontra relativamente fixada enquanto sentido no conto. De algum modo, já representa a satisfação de necessidades como as de segurança e conforto, para personagens caracterizados de forma a não despertar grande simpatia. Contudo, é a visita de Camilo que vai, declaradamente, escancarar as "janelas fechadas" da "morada do indiferente Destino", e aí introduzir o olhar curioso do leitor (conduzido, é claro, pela supervisão do narrador).

A aproximação do universo que envolve a cartomante é descrita com lentidão. É possível sentir a ansiedade do personagem Camilo, estampada em cada gesto seu, em cada movimento. Estes gestos, em contrapartida, são acompanhados de respostas que só os fazem aumentar. Quando bate à porta, são necessárias várias repetições até que alguém venha atendê-lo. Atendido, é preciso subir ao sótão por uma escada precária, um caminho escuro. $\mathrm{E}$, lá dentro, é preciso obedecer à ordem de um ritual que, tão logo se inicia, o toma de arrebatamento.

Diante da cartomante, Camilo é um ser passivo e dócil como um cão acariciado. Não se move, não age, é conduzido. E o que ouve, Ihe provoca prazer tal que seu comportamento é de êxtase e paralisia: "Camilo tinha os olhos nela, curioso e ansioso." (p.21) e "estava deslumbrado" (p. 21), "Camilo estremeceu como se fosse a mão da própria sibila..." (p. 22). Ou, ainda:

\footnotetext{
"Tudo Ihe parecia agora melhor, as outras cousas traziam outro aspecto, o céu estava límpido e as caras joviais. Chegou a rir dos seus receios, que chamou pueris; recordou os termos da carta de Vilela e reconheceu que eram íntimos e familiares. Onde é que ele lhe descobrira a ameaça?" (MACHADO DE ASSIS, 7, p. 23)
}

Por outro lado, além das reações de Camilo, as ações da cartomante ressaltam com especial importância. Se Camilo perfaz o típico ser manipulado, ela encarna a destreza e a dissimulação necessárias ao manipulador. Sua casa é caracterizada pela pouca luz, pela degradação material, pela sujeira ("o corrimão pegajoso"): "Velhos trastes, paredes sombrias, um ar de pobreza, que antes aumentava do que destruía 0 prestígio." (p. 20)

Ora, a ambigüidade dos sinais é evidente: Camilo lê o que está em torno de si como marcas da "indiferença" do Destino... Ele lê o que precisa: a cartomante, às voltas com a vida e a morte não se interessa pelas ocupações banais dos comuns dos mortais, nem lhe interessam ocupações materiais, beleza estética, aparência de prosperidade, estes valores tão burgueses e banais...

Camilo lê assim, e o narrador ironiza cruelmente sua dependência ingênua. Quando ele vai embora, já devidamente acalmado, e lhe dá uma nota de dez mil-réis, "os olhos da cartomante fuzilaram". Sendo de dois mil-réis o pagamento usual, percebe-se que ela não era tão indiferente assim a questões materiais. De mais a mais, Camilo a deixa e vai feliz encontrar um Vilela furioso e transtornado que o assassina diante do cadáver ensanguentado de Rita.

Esta morte obriga o leitor que ainda não o fizera a se voltar desconfiado para as atitudes da cartomante e para os sinais ambíguos - como já dissemos - através dos quais ela é caracterizada:

"A cartomante fê-lo sentar diante da mesa, e sentou-se do lado oposto, com as costas para a janela, de maneira que a pouca luz de fora batia em cheio no rosto de Camilo. Abriu uma gaveta e tirou um baralho de cartas compridas e enxovalhadas. Enquanto as baralhava, rapidamente, olhava para ele, não de rosto, mas por baixo dos olhos. Era uma mulher de quarenta anos, italiana, morena e magra, com grandes olhos sonsos e agudos. Voltou três cartas sobre a mesa, e disse-lhe:

-Vejamos primeiro o que é que o traz aqui. 0 senhor tem um 
grande susto ...

Camilo, maravilhado, fez um gesto afirmativo.

-E quer saber, continuou ela, se Ihe acontecerá alguma cousa ou não...

-A mim e a ela, explicou vivamente ele.

A cartomante não sorriu; disse-Ihe só que esperasse. Rápido

pegou outra vez das cartas e baralhou-as, com os longos

dedos finos, de unhas descuradas; baralhou-as bem, transpôs os maços, uma, duas, três vezes; depois começou a estendê-las. Camilo tinha os olhos nela ..." (MACHADO DE ASSIS, 7, p.20-21)

Trata-se de um evidente processo de engodo. A luz no rosto do personagem permitindo que ele seja melhor observado. $\mathrm{O}$ jogo com as cartas dando tempo à cartomante para pensar e examinar as reações de Camilo. Os olhos sonsos e agudos: aparentemente sonsos, mas sobretudo agudos. A "adivinhação" do susto estampado no rosto de Camilo, sua ajuda para que ela percebesse que o problema era amoroso.

A ironia do narrador se revela inclusive no cuidado com que ele descreve a personagem da cartomante que assume, assim, um sentido emblemático. Menos que a particularização de um ser, ela parece representar mesmo um estilo de vida. Uma profissão que é apenas um jogo de esperteza, um processo de exploração do desespero e da fraqueza alheia. O "indiferente Destino" não é indiferente de modo algum, mas absolutamente comprometido com a produção de satisfação no "freguês" que, bem sugestionado, tanto pode remunerar melhor quanto voltar outra vez e mesmo indicar os serviços a alguém igualmente desesperado.

\section{UMA QUESTÃO}

Retomando o que já fora apresentado, refazendo a idéia já explorada, iluminando com novas luzes um caminho já trilhado, este narrador constrói um foco narrativo que se caracteriza pelo movimento. Camilo e Rita têm suas posições constan- temente reavaliadas sobretudo pelo olhar crítico do narrador.

A princípio, este permite uma quase adesão emocional diante da harmonia do casal. Parodia a fala de Rita e revela que ela o dissera "por outras palavras" (Neutro, não?). A seguir, parece quase aderir aos valores céticos de Camilo. Logo, porém, renuncia aos dois e se mostra francamente distanciado de um e de outro, através da caracterização deste e daquele e da descrição de suas visitas à cartomante. Por fim, os reduz ao mesmo denominador comum: a fraqueza e a indignidade da morte por vingança.

É quando percebemos que a cartomante é a personagem central do conto: tanto Camilo, quanto Rita, quanto Vilela são pretextos úteis apenas para colocá-la em cena. O núcleo da narrativa não está no drama amoroso em si. Da mesma forma, não há elementos suficientes para que se creia que tal núcleo seja a discussão da fidelidade, da validade ou não do crime passional, ou outras questões similares.

A exclusão do personagem Vilela da narrativa é mesmo um fator que ajuda a evitar falsos caminhos. $O$ personagem, embora pudesse ser o centro dramático de um triângulo amoroso como este - em que os amantes não sentem culpa ou qualquer outro conflito psicológico - é muito pouco considerado na narrativa. Aliás, é desconsiderado. Não é ele o porta-voz do problema humano colocado pelo texto. Seu ciúme, sua dor, seu conflito, nada disto é posto em questão.

D a mesma forma, não se trata de uma análise, por exemplo, da validade do casamento enquanto instituição, tema tão machadiano. O casal formado à revelia do institucional é tão sem grandeza, é tão banal,é tão medíocre que descarta o tema. Além disso, não se enfatiza nem o conflito do par, nem a sua felicidade: a tudo o narrador confere igual desimportância.

De forma que, depois de deixar a atenção se perder em pistas falsas, subitamente salta aos olhos do leitor que a narrativa, já em seu título, quer explorar a personagem da cartomante. Para fazê-lo, a técnica utilizada não poderia ter sido mais feliz. Como uma cartomante,o narrador dispersa a atenção do interlocutor. Como uma cartomante, ele cria um ritual e altera seguidas vezes a ordem do baralho e seguidas vezes mostra esta ou aquela carta como a responsável pelo sentido atribuído aos dados do mundo. 
Mas o sentido não está nas cartas. O sentido não está em Vilela, Camilo, ou Rita. As cartas, como as personagens, são só o recurso que se utilizou para se buscar o sentido onde de fato ele está: no próprio interlocutor. O ritual é apenas necessário, mas nada resolve por si.

E, como a cartomante joga com a ansiedade de quem a procura, o narrador joga com a identificação de quem o lê. Não é possível, de saída, que um leitor se identifique com a universal questão hamletiana? Mas, se ele o faz, logo se defronta com o riso de Camilo. E se ele se identifica com o riso de Camilo, logo tem que refletir sobre seu desespero.

A diferença, fundamental porque decisiva, é que, enquanto a cartomante ganha a vida iludindo, o narrador machadiano a ganha pedindo que se desconfie da ilusão. Por isso mesmo, quando o conto termina, qualquer identificação emocional com qualquer personagem da narrativa fica impedida e só pode ser obtida à força de se negligenciar a organização estrutural do texto que só permite a ironia (ver JAUSS, 6). Os personagens não são heróis: impossível estabelecer relações amigáveis com qualquer um deles. Vilela é o ausente. Camilo, o fraco. Rita, a leviana. A cartomante, por sua vez, a manipuladora inescrupulosa.

Então, resta desconfiar da ilusão é desconfiar integralmente do processo: desconfiar do que aparentemente nos alivie e console. Pode ser jogo. Pode ser ritual de engodo. Isto, obviamente, inclui a literatura de modo generalizado e este conto em específico. E de modo algum podemos esquecer, então, que até este narrador-cartomante pode estar a produzir mistificação.

Se o problema é a aparência dos rituais contraposta ao que eles escondem de essencial, se é este o problema em questão, então a literatura é ela própria um ritual à busca de sentido. E nosso narrador leva seu leitor a encará-lo, até a ele (narrador), de modo crítico e distanciado.

Quando, por exemplo, já no primeiro parágrafo do conto, ele incorpora, como elemento constitutivo do repertório da narrativa, Hamlet, de Shakespeare, e vem retomá-lo para ajudar Camilo a decidir-se pela visita à cartomante, há algo de podre na estratégia utilizada (ver ISER, 4).

O fato é que, quando se faz referência a Hamlet, em termos de senso comum, o que primeiro vem à mente são as temáticas do adultério, da vingança auxiliada pelo sobrenatural, da dúvida e da destinação trágica dos homens. Ora, diante disto, teríamos uma "clara" alusão ao próprio conteúdo de "A cartomante". O conto caminha, mais ou menos intensamente, por estas vias.

No entanto, Hamlet (e a cartomante) nas mãos de Shakespeare (e nas de Machado) rendeu bem mais do que isto. Vale a citação:

\begin{abstract}
"Só que o personagem Hamlet de Shakespeare não é apenas o executor de uma vingança, mas um ser humano que reflete sobre seus atos e sobre a vida, que hesita antes de agir, analisando as possiveis consequências das ações. É esta "indecisão" que o caracteriza e que fascina o espectador. Provavelmente, o Hamlet mítico, o primitivo Hamlet (Ur-Hamlet, conforme o prefixo alemão) era um herói agressivo, um vingador implacável, mais próximo do estilo épico. Shakespeare, ao adaptar para o palco a antiga lenda, conferiu ao personagem o caráter perplexo e problemático, próprio do homem de sua época. Assim, o centro do drama se desloca da vingança pura e simples para o estudo das reações dos fatos no espírito do protagonista." (D'ONOFRIO, 2, p. 307)
\end{abstract}

Diante do texto atribuído a Shakespeare, uma rápida rememoração pode, então, nos fazer pensar apenas em adultério e vingança. Se pensamos assim, o narrador nos apanhou. Mas, se aprofundamos a leitura do texto citado, podemos aprofundar a do novo texto diante de nós. E, se Hamlet tem o centro do drama deslocado para o estudo das reações dos fatos no espírito do protagonista, "A cartomante", vai um pouco além.

Pelo estudo das reações de Camilo e Rita diante dos fatos e diante da cartomante, o narrador praticamente obriga o leitor a avaliá-los criticamente. Obriga-o a preencher as lacunas estrategicamente deixadas aqui e ali, a trazer para o texto um olhar menos ingênuo e a lançar tal olhar sobre si mesmo (ver 
ISER, 5).

De resto, se o leitor não o fizer, estará pego em armadilha. A cartomante vai enredá-lo. Enredado, morre nas mãos do marido que se vinga. E o marido que se vinga é o próprio narrador. Sua visão será privilegiada em relação à do leitor e com seu hábito irônico de se rir diante da mediocridade intelectual de Rita e da fraqueza moral de Camilo, seu riso irá se voltar, agora, sobre o próprio leitor (ver SHOLLES, 8). Ironizado, este nem o perceberá. E deixará o conto um pouco perplexo com a morte do casal, sem perceber uma morte que é sua.

Porque seu principal papel como leitor da modernidade é precisamente perceber tal ironia e se apropriar do universo literário utilizando-a como arma e como escudo (ver WEIMANN, 9). Porque, a partir de escritores como Machado de Assis, deixou de ser parte do processo a aceitação do espectro do rei. Passou a ser necessário descrer até daquele que nos "adoça" o momento: descrer do próprio texto. Lê-lo pela via da desmistificação.

E "ser ou não ser" já não é a única questão. Afinal, há, já, muito mais coisas entre o céu e a terra, e a carnificina dos finais grandiosos de outros tempos foi substituída por um risinho sardônico que nos obriga a não morrer e a assumir a complexidade da vida.

Passando a palavra a quem pôde dizê-lo melhor:

"Chegou um tempo em que não adianta morrer. Chegou um tempo em que a vida é uma ordem.

A vida apenas, sem mistificação."

"Os ombros suportam o mundo", Carlos Drummond de Andrade

\section{REFERÊNCIAS BIBLIOGRÁFICAS}

1. BOOTH, W. "Distance and point-of-view: an essay in classification". In: STEVICK, P. (ed.) The Theory of the Novel. New York-London : The Free Press-Coolier Macmillan, (1967), pp. 87-107.

2. D'ONOFRIO, S. Literatura ocidental: autores e obras fundamentais. São Paulo: Ática, 1990.

3. FRIEDMAN, N. "Point-of-view in fiction: the development of a critical concept". In: STEVICK, P. (ed.) The Theory of the Novel. New York - London : The Free Press-Coolier Macmillan, (1967), pp. 108-37.

4. ISER, W. Narrative strategies as a means of communication. ( ... )

5. __. "The reader as a component part of the realistic novel: esthetic effects in Thackeray's Vanity Fair" In: __. The implied reader: patterns of communication in prose fiction from Bunnyan to Beckett. 2. ed. Baltimore - London: The John Hopkins University Press, [1975]. pp. 101- 20.

6. JAUSS, H.R. "Levels of identification of hero and audience". In: __. New Literary History. V, 1973. pp. $283,317$.

7. MACHADO DE ASSIS. A cartomante. In:__. Várias Histórias. (Obras Completas de Machado de Assis, v. 14). São Paulo: Mérito, 1962.

8. SHOLES, R. \& KELLOG, R. Point of view in narrative. In:_ The nature of narrative. London Oxford. New York, Oxford University

Press, [1966]. pp. 240-82

9. WEIMANN, R. Structure and history in narrative perspective: The problem of point of view reconsidered. In: _. Structure and society in literary history: Studies in the history and theory of historical criticism. Baltimore - London : The John Hopkins University Press, [1984] pp.234-36. 